\title{
INOVASI KURIKULUM MADRASAH DI PESANTREN KABUPATEN BANYUWANGI DALAM MENGIMPLEMENTASIKAN CIVIC EDUCATION
}

\author{
Moh. Harun Al Rosid, Eko Budiywono, Mamlukhah \\ Institut Agama Islam Darussalam Blokagung Banyuwangi \\ E-mail: harun2939@gmail.com. ekobeye31@gmail.com. \\ mamlukhah0876@gmail.com
}

\begin{abstract}
Reasons for Choosing Side-by-Side, namely: (1) Madrasas need curriculum innovations in order to contribute to the success of madrasa goals that are in line with the objectives of national education; (2) Madrasas have never received civic education assistance from the Banyuwangi district government; (3) Madrasah students need an understanding of civic education, especially insight into the archipelago as a counterweight to understanding religion and nation in the Unitary State of the Republic of Indonesia for the provision of living in a pluralistic society. The approach used is Participatory Action Research (PAR). The conclusion obtained from the results of this service is that the madrasah curriculum innovation at the pesantren is important, given that Islamic religious education at the pesantren contributes greatly to the Republic of Indonesia as a moral fortress as well as a stronghold of radicalism. Positive responses and stakeholder support are also a great motivation for the smoothness and success of the madrasah-based community service program carried out at the largest madrasah diniyah in Banyuwangi district, hoping that it could become a reference and barometer for the madrasah diniyah in Banyuwangi district.

\section{Keywords: Madrasah Curriculum Innovation, Civic Education Implementation}

\begin{abstract}
Abstrak
Alasan memilih Dampingan, yaitu : (1) Madrasah butuh inovasi kurikulum guna turut serta mensukseskan tujuan madrasah yang sejalan dengan tujuan pendidkan nasional; (2) Madrasah belum pernah mendapatkan pendampingan civic education dari pemerintah daerah kabupaten Banyuwangi; (3) Peserta didik madrasah membutuhkan pemahaman civic education khususnya wawasan nusantara sebagai penyeimbang pemahaman beragama dan berbangsa di Negara Kesatuan Republik Indonesia guna bekal hidup di masyarakat yang majemuk. Pendekatan yangdigunakan adalah dengan Participatory Action Research (PAR). Kesimpulan yang didapat dari hasil pengabdian ini adalah inovasi kurikulum madrasah di pesantren itu penting, mengingat pendidikan keagamaan Islam di pesantren berkontribusi besar bagi NKRI yakni sebagai benteng moral sekaligus benteng radikalisme. Respon positif serta dukungan stakeholder juga merupakan motivasi besar terhadap kelancaran dan kesuksesan program kegiatan pengabdian kepada masyarakat berbasis madrasah yang dilaksanakan pada madrasah diniyah terbesar di kabupaten Banyuwangi ini, harapannya bisa menjadi rujukan serta barometer bagi madrasah diniyah se-kabupaten Banyuwangi.
\end{abstract}

Kata Kunci : Inovasi Kurikulum Madrasah, Implementasi Civic Education 


\section{A. Pendahuluan}

Inovasi kurikulum madrasah yang ada di pesantren sangatlah penting untuk menjawab dan memenuhi kebutuhan dan tuntutan santri dan masayarakat, agar madrasah dipesantren tidak tertinggal dengan perkembangan dan perubahan zaman. Tentunya dalam berinovasi tidak merubah total kurikulum dipesantren, akan tetapi inovasi yang dimaksud adalah penambahan mata pelajaran atau penyisipan nilai-nilai yang diinginkan. Kurikulum yang ada di pesantren terdiri dari tiga aspek utama, yaitu perencanaan, pelaksanaan dan evaluasi.

Perencanaan kurikulum dimulai dengan kegiatan kajian pada aspek kebutuhan (needs assessment). Kajian kebutuhan tersebut dihubungkandengan perkembangan zaman, dimana pendidikan itu berbasis kepada kecakapan hidup (life skills) yang sesuai dengan lingkungan santri. Pelaksanaan kurikulum juga mempunyai tiga pendekatan kecerdasan majemuk (multiple inteligence) dan pembelajaran kontekstual (contextual teaching and learning). Sedang evaluasinya menerapakan penilaian secara universal terhadap semua kompetensi santri (authentic assessment).

Kurikulum di pesantren selama ini mungkin masih belum begitu diperhatikan, karena dianggap klasik dan tidak dapat diinovasikan. Jika kita berfikir lebih jauh, ada baiknya bila pesantren membuat sebuah gagasan/ide dalam mengembangkan kurikulumnya. Terkait inovasi kurikulum madrasah pesantren bahwa sebenarnya civic education (pendidikan kewarganegaraan) ini juga sangatlah baik bila diterapkan di madrasah pesantren karena nilai yang terdapat padacivic education sejalan dengan ajaran agama Islam. Di dalam civic education mengandung nilai-nilai beragama, berbangsa dan bernegara الدين والأمة والدولة(aldiyn wal'umat waldawlat). Hal ini penting sekali guna menghindari pemahaman yang salah dalam beragama. Karena gerakan yang bisa mengancam keutuhan Negara Kesatuan Republik Indonesia (NKRI) misalnya: mendirikan negara Islam (khilafah Islamiyah) terorisme, etnosentrisme, primordialisme dan lain sebagainya, ini bisa muncul dari pemahaman beragama yang kurang tepat, butuh keseimbangan antara beragama, berbangsa dan bernegara. Maka civic education dipandang sangat tepat untuk diterapkan di madrasah pesantren guna memberikan pemahaman konsep beragama, berbangsa dan bernegara bagi peserta didik/santri 
di madrasah pesantren sebagai bekal hidup kelak di masyarakat dan sekaligus inovasi kurikulum di madrasah pesantren.

Dari uraian diatas dapat diambil pemahaman bahwa hakikat pendidikan sangatlah penting, baik itu di lembaga formal dan informal. Sistem pendidikan adalah keterpaduan dari seluruh satuan padaaktivitas pendidikan yang saling berkaitan satu dengan yang lainnya gunaefektifitas dan efisiensi tujuan pendidikan.Pesantren dengan madrasahnyajuga berkontribusi besar mewujudkan tujuan pendidikan nasional, maka tim pengabdian tertarik untuk melaksanakan pengabdian terkait inovasi kurikulum madrasah pesantren.

\section{Alasan Memilih Dampingan}

1. Madrasah butuh inovasi kurikulum guna turut serta mensukseskan tujuan madrasah yang sejalan dengan tujuan pendidkan nasional

2. Madrasah belum pernah mendapatkan pendampingan civic education dari pemerintah daerah kabupaten Banyuwangi

3. Peserta didik madrasah membutuhkan pemahaman civic education khususnya wawasan nusantara sebagai penyeimbang pemahaman beragama dan berbangsa di Negara Kesatuan Republik Indonesia guna bekal hidup di masyarakat yang majemuk

\section{Kondisi dampingan yang diharapkan}

1. Pesantren di kabupaten Banyuwangi mulai berinovasi pada kurikulumnya tanpa harus keluar dari tujuan dan visi misi pesantren.

2. Kepala madrasah, wakil bidang kurikulum di kabupaten Banyuwangi mempunyai penguasaan dan pemahamancivic education yang baik

3. Peserta didik (santri) di kabupaten Banyuwangi memperoleh pemahaman civic education yang baik dalam penguasaan wawasan kebangsaan dan bernegara sesuai dengan Pancasila dan UUD 1945

4. Pemahaman konsep wawasan nusantara sebagai pengembangan faham civic education menjadi bekal hidup berbangsa dan bernegara bagi masyarakat yang ada di pesantren kabupaten Banyuwangi khususnya dan masyarakat Indonesia pada umumnya 
5. Madrasah di pesantren kabupaten Banyuwangi bisa menyelaraskan tujuan pendidikannya dengan tujuan pendidikan nasional, sehingga ada keseimbangan berfikir dalam mendalami agama dan bermasyarakat

6. Madrasah di pesantren kabupaten Banyuwangi bersinergi dengan pemerintah, menanggulangi gerakan yang mengancam keutuhan NKRI.

\section{B. Landasan Teori}

1. Inovasi Kurikulum. Inovasi kurikulum berarti suatu ide, gagasan, atau tindakan tindakan tertentu dalam bidang kurikulum yang dianggap baru untuk memecahkan masalah pendidikan (Sanjaya Wina. 2009). Kedudukan kurikulum pentingpada proses pendidikan. Kurikulum memberikan arahanpada aktifitas pendidikan guna optimalisasi tujuan pendidikan. Kurikulum juga suatu rencana pendidikan, sebagai pedoman tentang jenis, ruang lingkup, isi, dan proses pendidikan (Sukmadinata. 2001).

2. Ciri-Ciri Inovasi Kurikulum. Ciri-ciri suatu inovasi yang dikemukakan oleh Rogers : (1) Adanya Keuntungan relatif (Relative Advantages), yaitu sejauh mana inovasi dianggap menguntungkan bagi penerimanya; (2) Kompatibel (compatibility) dan adanya kesepahaman, yaitu tingkat kesesuaian inovasi dengan nilai, pengalaman lalu dan kebutuhan dari penerima; (3) Memiliki Derajat Kompleksitas (complexity), yaitu tingkat kesukaran untuk memahami dan menggunakan inovasi bagi penerimanya; (4) Trialibilitas (trialibility), artinya sampai sejauh mana suatu inovasi dapat diujicobakan keandalan dan manfaatnya; (5) Dapat diamati (observability), yaitu mudah tidaknya diamati suatu hasil inovasi. Suatu inovasi yang hasilnya mudah diamati akan makin cepat diterima oleh masyarakat.

3. Kalsifikasi pesantren dan Kurikulum Madrasah Pesantren

a. Klasifikasi pesantren. Kementrian Agama Republik Indonesia dalam hal ini membagi bentuk pondok pesantren menjadi empat bentuk yang tertuang dalam Peraturan Menteri Agama Nomor 3 Tahun 1979 tentang bantuan pondok pesantren menjadi 4 (empat): (1) Pesantren tipe A adalah pesantren yang seluruhnya dilaksanakan secara tradisional; (2) Pesantren tipe $\mathrm{B}$ adalah pesantren yang menyelenggarakan pengajaran secara 
klasikal (madrasah); (3) Pesantren tipe $\mathrm{C}$ adalah pesanten yang hanya merupakan asrama, sedangkan santrinya belajar diluar; (4) Pesantren tipe $\mathrm{D}$ adalah pesantren yang menyelenggarakan sistem ponpes sekaligus sistem sekolah dan madrasah.

b. Kurikulum Madrasah Pesantren. Menurut Abdurrahman Wahid, kurikulum yang berkembang dipesantren memperlihat pola yang tetap, pola tersebut dapat dilihat sebagai berikut: (1) Kurikulum itu ditujukan untuk mencetak ulama di kemudian hari; (2) Struktur kurikulum itu berupa pengajaran ilmu pengetahuan agama dalam segenap tingkatannya dan pemberian pendidikannya dalam bentuk bimbingan kepada santri secara lansung dari kyai/gurunya; (3) Secara universal, bahwa kurikulum pendidikan pesantren bersifat fleksibel, dalam artian setiap santri mempunyai kesempatan menyusun kurikulumnya sendiri sepenuhnya atau sesuai dengan kebutuhannya, bahkan dalam pesantren memilki sistem pendidikan yang berbentuk sekolah. Realitas di lapangan bahwa sejak semula masingmasing madrasah diniyah takmiliyah atau biasa disebut madin dikembangkan di berbagai daerah dengan karakteristik dan kekhasan tersendiri menjadi kekuatan bagi penerapan kurikulum yang sesuai dengan kebutuhan lokal maupun nasional. Kurikulum madrasah diniyah disesuaikan dengan jenjang pendidikan yang ada yaitu : (a) Kurikulum Madrasah Diniyah Takmiliyah Awwaliyah (MDTA) yang ditempuh dalam 4 (empat) tahun masa belajar dari kelas 1 hingga kelas 4 dengan 18 jam per minggu; (b) Kurikulum Madrasah Diniyah Takmiliyah Wustha (MDTW) yang ditempuh dalam 2 (dua) tahun masa belajar dari kelas 1 hingga kelas 2 dengan 18 jam per minggu; (c) Kurikulum Madrasah Diniyah Takmiliyah Ulya (MDTU) yang ditempuh dalam 2 (dua) tahun masa belajar dari kelas 1 hingga kelas 2 dengan 18 jam per minggu

\section{Civic Education}

Secara bahasa istilah civic education oleh beberapa pakar diterjemahkan dalam bahasa Indonesia menjadi Pendidikan Kewargaan dan Pendidikan Kewarganegaraan. Pengertian Civic Education menurut beberapa ahli; Henry Randall Waiteyang dikutip Ruslina (2006:4) mendefinisikan bahwa Civic 
Education adalah ilmu pengetahuan yang membahas hubungan seseorang dengan orang lain dalam perkumpulan yang terorganisir,hubungan seorang individu dengan negara Civic education suatu budang kajian yang mempunyai obyek telaah kebajikan dan budaya kewarganegaraan dengan menggunakan disiplin ilmu pendidikan dan ilmu politik.

Menurut Azyumardi Azra (2003) Pendidikan kewarganegaraan (Civic Education) adalah pendidikan yang cakupannya lebih besar daripada pendidikan demokrasi dan HAM harena mencakup kajian yang lebih luas, seperti: pemerintahan, konstitusi, lembaga-lembaga demokrasi, rule of law, hak dan kewajiban warga negara, proses demokrasi, partisipasi aktif dan keterlibatan masyarakat dalam pembentukan masyarakat madani, dan sebagainya.

\section{Metode Penelitian}

1. Model pengabdian dan penentuan fokus

Model pengabdian yang digunakan adalah Participatory Action Research (PAR). PAR adalah metode riset yang dilaksanakan secara partisipatif di antara warga masyarakat dalam suatu komunitas aras bawah yang semangatnya untuk mendorong terjadinya aksi-aksi transformatif melakukan pembebasan masyarakat dari belenggu ideologi dan relasi kekuasan (perubahan kondisi hidup yang lebih baik). Dalam pengabdian ini yang menjadi fokus utama pengabdian adalah inovasi kurikulum dalam mengimplementasikan civic education.

2. Lokasi/obyek pengabdian:Madrasah Diniyyah al-Amiriyyah Blokagung merupakan madrasah diniyah terbesar di kabupaten Banyuwangi.

3. Alat analisis yang digunakan SWOT

\section{Hasil dan Pembahasan}

\section{Strategi Pelaksanaan Pendampingan Inovasi Kurikulum}

\section{Penggalian Data di Madrasah}

Dimulai dengan observasi, pada tahap ini tim pengabdian mendatangi Madrasah Diniyah al-Amiriyyah Blokagung notabene 
madrasah yang fokus pada pendidikan diniyah dan merupakan madrasah diniyah terbesar di kabupaten Banyuwangi dengan jumlah siswa lebih dari 5000 santri. Observasi yang dilakukan tim pengabdi pada awal sampai pertengahan bulan Juni 2018 ini menghasilkan beberapa temuan pada Madrasah Diniyah al-Amiriyyah Blokagung diantaranya yaitu:

a. Telah memiliki sertifikat muadalah dengan nomor 2791 Mei tahun 2017

b. Belum memiliki pedoman kurikulum, khususnya terkait materi Civic Education

c. Belum memiliki tenaga ahli yang mengampu materi Civic Education

d. Belum ada alokasi khusus yang memadai untuk pembelajaran materi Civic Education

e. Pimpinan dan pengelolanya sangat mendukung pada implementasi materi Civic Education

f. Telah ada kegiatan implentasi Civic Education berupa:

1) Pelaksanaan upacara peringatan kemerdekaan Republik Indonesia oleh seluruh santri di halaman pesantren

2) Pemasangan bendera merah putih di kantor madrasah

3) Pemasangan gambar garuda pancasila, presiden dan wakil presiden di kantor madrasah dan di seluruh kelas

4) Menyanyikan lagu kebangsaan Indonesia raya sebelum melaksanakan kegiatan seminar, pelatihan, workshop dan kegiatan resmi lainnya

5) Memperingati hari-hari besar Nasional, misalnya: peringatan Sumpah Pemuda, Hari Pendidikan Nasional, Hari santri dst.

Beberapa data hasil observasi di atas juga dilengkapi dengan hasil wawancara dengan stakeholder terkait yaitu kepala madrasah, ustadz dan santri madrasah diniyah al-Amiriyyah Blokagung:

a. Kepala madrasah

Menurut kepala madrasah diniyah al-Amiriyyah Blokagung, Civic Education belum ada pedoman pembelajarannya, tapi dalam tataran implementasi sudah dilaksanakan dan didukung sepenuhnya. 
"Kami memang belum punya pedoman Civic Education sebagai bahan ajar tapi kami sangat mendukung setiap kegiatan yang merupakan implementasi Civic Education, mulai dari upacara sampai peringatan hari besar nasional, pun menyayikan lagu Indonesia raya sebelum kegiatan resmi dan memasang gambar garuda pancasila, presiden dan wakil presiden sekaligus mengibarkan bendera merah putih".

\section{Gambar 1 : Wawancara dengan Kepala Madrasah Diniyah Blokagung,}

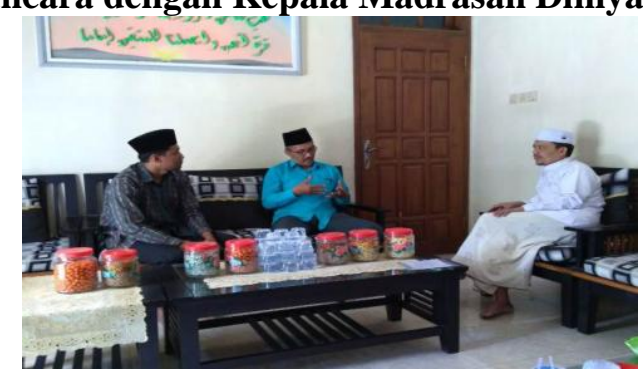

Sumber: Data Lapangan. 2018

Hasil wawancara tersebut menunjukkan bahwa ada kepedulian besar dari kepala madrasah diniyah al-Amiriyyah Blokagung dalam mendukung implementasi Civic Education sebagai bukti keterlibatan menggerakkan santri pada semangat cinta tanah air, Indonesia.

b. Ustadz

Keterangan yang disampaikan oleh ustadz Nizam Fahmi, wakil kepala madrasah bidang kurikulum, terkait inovasi kurikulum, khususnya yang berbasis Civic Education adalah hal yang sangat diharapkan mengingat santrinya yang berasal dari banyak daerah tersebar di seluruh kepulauan Indonesia, maka sangat penting nilainilai yang ada pada Civic Education dibentuk pada suatu pedoman pembelajaran agar lebih mudah dalam penyampaiannya kepada santri, sehingga lebih mudah difahami dan diterapkan dalam kehidupannya sehari-hari.

"Kami sangat berharap ada pembinaan dan pendampingan kepada kami untuk membuat pedoman kurikulum yang didalamnya juga mengakomodir kurikulum untuk mata pelajaran Civic Education karena santri madrasah diniyah al-Amiriyyah itu berasal dari seluruh daerah di kepulauan Indonesia, perlu diberikan penanaman nilai-nilai penting yang ada pada Civic Education, misalnya nilai persatuan, kebhinnekaan, kemanusiaan, gotong-royong dan sebagainya". 


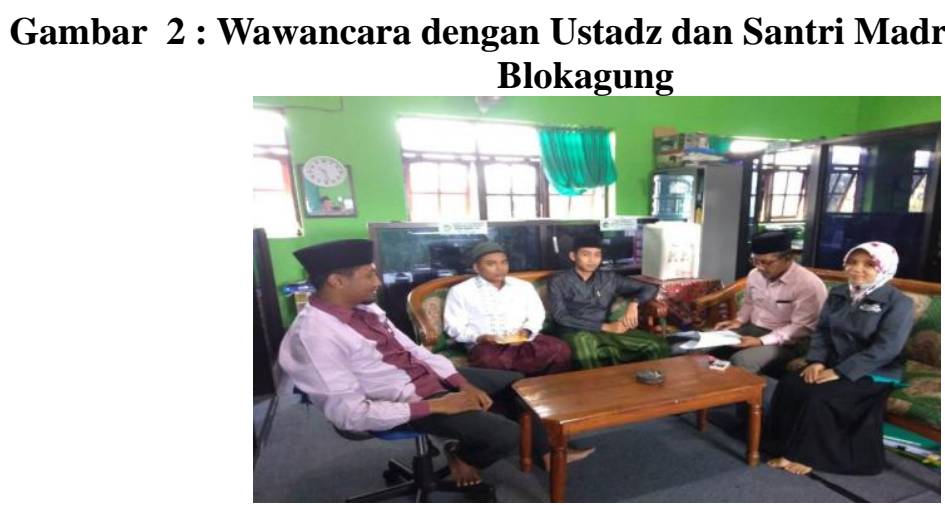

Sumber: Data Lapangan. 2018

Keterangan yang disampaikan oleh Ustadz Nizam Fahmi dalam tugasnya sebagai wakil kepala madrasah diniyah al-Amiriyyah Blokagung perlu didukung dengan kegiatan riil berupa pendampingan inovasi kurikulum oleh tenaga ahli, khususnya untuk materi Civic Education agar bisa mudah difahami dan diterapkan oleh santri dengan baik dan benar pada kehidupan santri yang majemuk dengan latar belakang daerah dari seluruh kepualaun Indonesia.

c. Santri

Ada banyak keinginan santri pada tim pengabdian yang terkait dengan pembelajaran Civic Education, diantaranya yaitu sebagaimana yang disampaikan oleh Himatul Muyyasaroh, santri kelas IV Ula, yaitu: adanya alokasi khusus pembelajaran Civic Education, materi Civic Education diberikan oleh tenaga ahli yang menguasai materi sekaligus punya metode yang baik dalam penyampainnya kepada santri agar mudah dimengerti, ada panduan khusus materi Civic Education yang disusun oleh tenaga ahli bersama stakeholder madrasah diniyah al-Amiriyyah Blokagung, penyetaraan materi Civic Education dengan materi-materi yang disampaikan pada madrasah diniyah al-Amiriyyah Blokagung karena materi ini sangat penting sebagai bahan untuk memupuk dan meningkatkan semangat cinta tanah air, Indonesia.

"Saya sangat berharap materi Civic Education itu punya jadual sebagaimana matarei lainnya, selain itu gurunya juga harus ahli dan menguasai materi tersebut, ada panduannya dan materi Civic Education itu disetarakan dengan materi lainnya, 
tujuannya agar santri termotivasi memahaminya seperti halnya semangatnya dalam memahami materi keaagmaan Islam”.

Keinginan santri dalam pernyataan di atas, membuktikan motivasinya yang besar dalam turut serta pada gerakan cinta tanah air, maka keinginan tersebut sangat perlu untuk diakomodir dalam bentuk pendampingan inovasi kurikulum, khususnya pada penyiapan materi Civic Education berbentuk pedoman sekaligus sampai pada pendampingan pada implementasi materi tersebut dalam kehidupan santri dengan latarbekang yang heterogen.

\section{Mengadakan Focus Group Discussion (FGD)}

FGD ini dilaksanakan pada hari kamis, 02 Agustus 2018 bertempat di ruang rapat yayasan pesantren Darussalam Blokagung dengan peserta: (a) Pakar pendidikan (kurikulum) dan tim wawasan kebangsaan Kesatuan Bangsa dan Politik (Kesbangpol); (b) Pengasuh dan kepala bidang pendidikan dan pengajaran pesantren Darussalam Blokagung Banyuwangi; (c) Ketua Robithoh Ma'ahidil Islamiyah (RMI) Banyuwangi; (d) Kepala bidang kepesantrenan pesantren Darussalam Blokagung Banyuwangi; (e) Kepala madrasah diniyah al-Amiriyyah Blokagung Banyuwangi; (f) Tim pengabdi.

Hasil dari FGD tersebut adalah kesepakatan peserta dalam rencana pelaksanaan pendampingan inovasi kurikulum pada madrasah diniyah alAmiriyyah Blokagung, khususnya pada implementasi Civic Education. Hal ini mengingat madrasah diniyah al-Amiriyyah Blokagung adalah madrasah terbesar di kabupaten Banyuwangi, sehingga menjadi rujukan dan barometer pendidikan diniyah di kabupaten Banyuwangi. Harapannya, kesuksesan pendampingan inovasi kurikulum pada implementasi Civic Education di madrasah diniyah al-Amiriyyah Blokagung oleh tim ahli juga bisa menjadi motivasi pada madrasah diniyah di kabupaten Banyuwangi.

Pada FGD tersebut juga disepakati tanggal, peserta dan narasumber workshop inovasi kurikulum madrasah diniyah pada implementasi Civic Education yaitu tanggal 4-5 September 2018 dengan peserta pengelola dan ustadz/ustadzah madrasah diniyah al-Amiriyyah Blokagung dan 
pematerinya adalah : (1) Kepala Bakesbangpol dan tim wawasan kebangsaan kabupaten Banyuwangi; (2) Kepala Seksi Pendidikan Diniyah dan Pesantren (Kasi. PD. Pontren) Kementerian Agama kabupaten Banyuwangi; (3) Penerima Beasiswa dan Peserta Program Doktoral Manajemen Pendidikan Islam Pesantren IAIN Jember.

Selain kesepakatan tersebut juga disepakati tindaklanjut dari workshop inovasi kurikulum madrasah diniyah dalam implementasi Civic Education, yaitu pendampingan kepada pengelola madrasah diniyah alAmiriyyah Blokagung dalam rangka penyusunan pedoman materi Civic Education, sebagai bahan ajar ustadz/ustadzah kepada santrinya agar lebih mudah difahami dan diaktualisasikan dalam kehidupan sehari-hari saat di tinggal pesantren maupun saat mereka sudah kembali ke kampung halamannya masing-masing.

\section{Workshop inovasi kurikulum dalam Implementasi Civic Education}

Pelaksanaan workshop inovasi kurikulum dalam implementasi Civic Education ini atas kerjasama stakeholder terkait diantaranya yaitu: (1) kepala madrasah Diniyah al-Amiriyyah Blokagung beserta seluruh stafnya; ketua Bakesbangpol beserta tim wawasan kebangsaan kabupaten Bayuwangi; (3) kepala kementerian agama kabupaten Banyuwangi beserta stafnya; (4) ketua RMI kabupaten Banyuwagi beserta stafnya; (5) tim pengabdi Institut Agama Islam Darussalam Blokagung Banyuwangi.

Pembukaan workshop inovasi kurikulum dalam implementasi Civic Education dihadiri oleh: (1) ketua Robithoh Ma'ahidil Islamiyyah (RMI) kabupaten Banyuwangi; (2) pengasuh pondok Pesantren Darussalam Blokagung Banyuwangi; (3) kepala bidang Pendidikan dan Pengajaran Pesantren Darussalam Blokagung Banyuwangi; (4) kepala Bidang Kepesantrenan Pesantren Darussalam Blokagung Banyuwangi; (5) Rektor Institut Agama Islam Darussalam Blokagung Banyuwnagi.

Kegiatan ini dilaksanakan selama dua hari, yakni hari Selasa sampai Rabu, tanggal 4-5 September 2018, bertempat di Aula KH. Mukhtar Syafa'at pesantren Darussalam Blokagung Banyuwangi dengan jumlah peserta mencapai 80 orang terdiri dari: (1) kepala dan wakil kepala 
madrasah diniyah al-Amiriyyah Blokagung; (2) ustadz/ustadzah madrasah diniyah al-Amiriyyah Blokagung; (3) perwakilan mahasantri Ma'had Ali Darussalam Blokagung; (4) perwakilan mahasiswa beasiswa madrasah diniyah Institut Agama Islam Darussalam Blokagung Banyuwangi.

Pertimbangan dari pelaksanaan workshop inovasi kurikulum dalam implementasi Civic Education selama dua ini adalah adanya aturan kebijakan dari pengasuh pesantren Darussalam Blokagung bahwa kegiatan ini difokuskan pada pagi sampai siang hari, mengingat siang-sore serta malam hari adalah kegiatan pesantren difokuskan pada pendidikan diniyah dan pengajian kitab salaf. Adapun materi, pemateri dan alokasi waktunya bisa dilihat pada tabel berikut:

Tabel 1: Materi Workshop Inovasi Kurikulum dalam Implementasi Civic Education

\begin{tabular}{|c|c|c|}
\hline Materi & Narasumber & Durasi \\
\hline $\begin{array}{l}\text { Kontribusi Madrasah Diniyyah } \\
\text { dan Pesantren dalam Pendidikan } \\
\text { di Indonesia sebagai Benteng } \\
\text { Moral dan Benteng Radikalisme }\end{array}$ & $\begin{array}{l}\text { Drs. H. Mastur, M.Pd.I } \\
\text { Kasi. PD. Pontren Kementerian } \\
\text { Agama Banyuwangi }\end{array}$ & 2 jam \\
\hline $\begin{array}{l}\text { Civic Education } \\
\text { (Wawasan Kebangsaan) sebagai } \\
\text { sebuah faham dan gerakan }\end{array}$ & $\begin{array}{l}\text { Drs. Wiyono, M.H. } \\
\text { Kepala Badan Kesatuan Bangsa dan } \\
\text { Politik Banyuwangi }\end{array}$ & 2 jam \\
\hline $\begin{array}{l}\text { ImplementasiCivic Education } \\
\text { dalam kemajemukan masyarakat } \\
\text { Indonesia }\end{array}$ & $\begin{array}{l}\text { Tim Wawasan Kebangsaan } \\
\text { kabupaten Banyuwangi }\end{array}$ & 2 jam \\
\hline $\begin{array}{l}\text { Inovasi Kurikulum Madrasah } \\
\text { Diniyyah di Pesantren dalam } \\
\text { Mewujudkan Mutu Pendidikan } \\
\text { Keagamaan Islam }\end{array}$ & $\begin{array}{l}\text { Siti Aimah, S.Pd.I., M.Si. } \\
\text { Penerima beasiswa pada program } \\
\text { Doktoral Manajemen Pendidikan } \\
\text { Islam Pesantren IAIN Jember }\end{array}$ & $2 \mathrm{jam}$ \\
\hline
\end{tabular}

Sumber: Data Lapangan. 2018

Berikut ini adalah dokumentasi nya

\section{Gambar 3 : Kepala Bakesbangpol dan Tim Wawasan Kebangsaan}

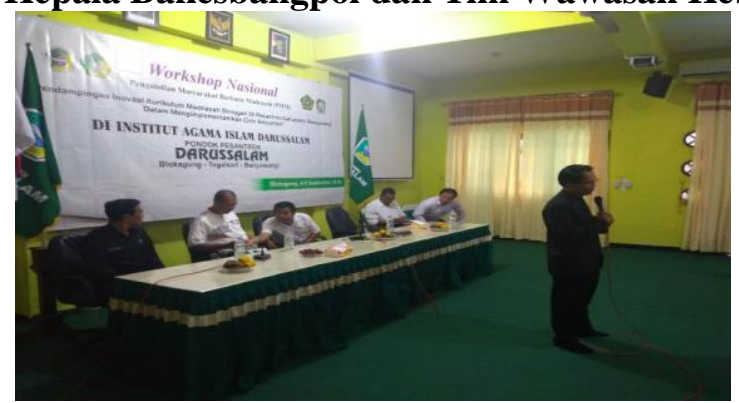

Sumber: Data Lapangan. 2018

Antusias peserta dalam kegiatan workshop inovasi kurikulum dalam implementasi Civic Education ini sangat baik, tampak dari kedisplinan 
peserta dan semangatnya dalam mengikui setiap sesi materi dari awal sampai akhir disertai dengan semangat mereka melalui banyaknya pertanyaan saat moderator membuka sesi tanya jawab. Bahkan peserta berharap kegiatan ini ada tindaklanjutnya, berupa pendampingan dalam penyusunan kurikulum berbasis Civic Education. Oleh karena itulah tim pengabdian Institut Agama Islam Darussalam Blokagung Banyuwangi merekomendasikan harapan peserta tersebut kepada kepala madrasah diniyah al-Amiriyyah Blokagung Banyuwangi untuk ditindaklanjuti bekerjasama dengan tim ahli dan stakeholder terkait.

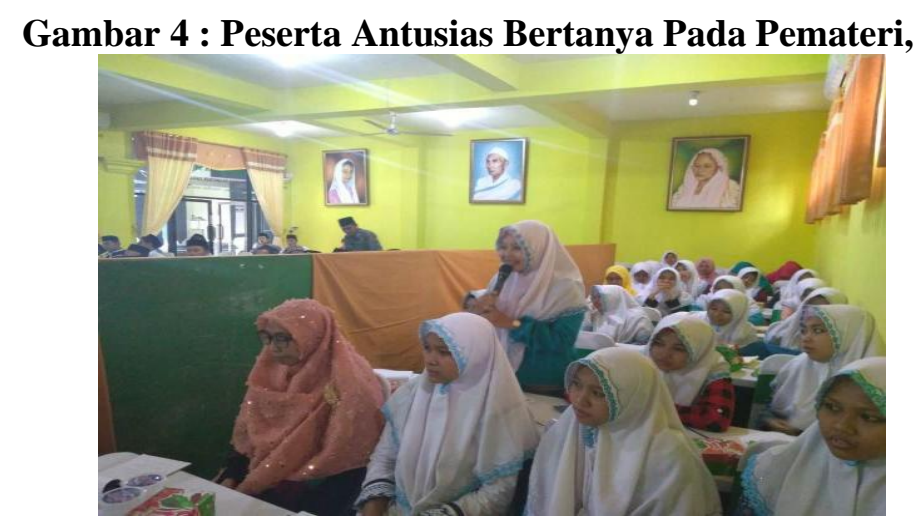

Sumber: Data Lapangan. 2018

4. Pelaksanaan Pendampingan Inovasi Kurikulum Dengan Penyusunan Kurikulum dalam Implementasi Civic Education

Kegiatan ini merupakan tindaklanjut dari workshop inovasi kurikulum dalam implementasi Civic Education yang telah dilaksanakan pada tanggal 4-5 September 2018 atas kesepakatan stakeholder pada Focus Group Discussion (FGD) yang dilaksanakan pada tanggal 2 Agustus 2018. Atas kebaikan hati dan dukungan yang luar biasa dari kepala Bakesbangpol dan tim wawasan kebangsaan kabupaten Banyuwangi serta kasi. PD. Pontren kementerian agama Islam kabupaten Banyuwangi yang turut serta membantu dan mendampingi pengelola madrasah diniyah al-Amiriyyah Blokagung dalam penyunan pedoman Civic Education sebagai bahan ajar ustdza/ustadzah kepada santri.

Kegiatan ini dilaksanakan selama lima hari mulai Senin-Rabu, tanggal 10-12 September 2018 bertempat di kantor madrasah diniyah al- 
Amiriyyah Blokagung. Adapun peserta dalam penyusunan pedoman Civic Education ini adalah: (1) kepala madrasah diniyah al-Amiriyyah Blokagung; (2) wakil kepala madrasah diniyah al-Amiriyyah Blokagung bidang kurikulum tingkat Ulya; (3) wakil kepala madrasah diniyah alAmiriyyah Blokagung bidang kurikulum tingkat Wustho; (4) wakil kepala madrasah diniyah al-Amiriyyah Blokagung bidang kurikulum tingkat Ula; (5) ustadz dan ustadzah materi akhlaq (moral/etika); (6) kader ustadz/ustadzah materi Civic Education; (7) perwakilan mahasantri Ma'had Ali Darussalam Blokagung. Sementara itu pendamping dalam penyusunan pedoman Civic Education adalah Tim Wawasan Kebangsaan kabupaten Banyuwangi, Kasi. PD. Pontren kabupaten Banyuwangi dan peserta program doktoral manajemen pendidikan Islam pesantren IAIN Jember.

Hasil dari penyusunan pedoman materi Civic Education ini berjenjang sesuai jenjang di madrasah diniyah al-Amiriyyah Blokagung dan menyesuaikan dengan lampiran permendiknas nomor 22 tahun 2006, yaitu: Ula, Wustho dan Ulya. Adapun ruang lingkup materi pada pedoman Civic Education adalah sebagai berikut:

Pedoman Civic Education tingkat ula: (a) persatuan dan kesatuan bangsa, meliputi; hidup rukun dalam perbedaan, cinta lingkungan, kebanggaan sebagai bangsa Indonesia, sumpah pemuda, keutuhan NKRI, partisipasi dalam pembelaan negara, sikap positif terhadap NKRI, keterbukaan dan jaminan keadilan; (b) norma, hukum dan peraturan, meliputi; tertib dalam kehidupan keluarga, tata tertib sekolah, norma yang berlaku di masyarakat, peraturan-peraturan daerah, norma-norma dalam kehidupan berbangsa dan bernegara, sistem hukum peradilan nasional, hukum dan peradilan internasional.

Pedoman Civic Education tingkat wustho: (a) Hak Asasi Manusia (HAM), meliputi; hak dan kewajiban anak, hak dan kewajiban anggota masyarakat, instrumen nasional dan internasional HAM, pemajuan, penghormatan dan perlindungan HAM; (b) kebutuhan warga negara, meliputi; hidup gotong royong, harga diri sebagai sebagai warga 
masyarakat, kebebasan berorganisasi, kemerdekaan mengeluarkan pendapat, menghargai keputusan bersama, prestasi diri, persamaan kedudukan warga negara; (c) konstitusi negara, meliputi; proklamasi kemerdekaan dan konstitusi yang pertama, konstitusi-konstitusi yang pernah digunakan di Indonesia, hubungan dasar negara dengan konstitusi.

Pedoman Civic Education tingkat ulya: (a) kekuasaan dan politik, meliputi; pemerintahan desa dan otonomi, pemerintahan pusat, demokrasi dan sistem politik, budaya politik, budaya demokrasi menuju masyarakat madani, sistem pemerintahan, pers dalam masyarakat demokrasi; (b) pancasila, meliputi; kedudukan pancasila sebagai dasar negara, proses perumusan pancasila sebagai dasar negara, pengamalan nilai-nilai pancasila dalam kehidupan sehari-hari, pancasila sebagai ideologi terbuka; (c) globalisasi meliputi; globalisasi di lingkungannya, politik luar negeri Indonesia di erdan organa globalisasi, dampak globaliasi, hubungan internasional dan organisasi internasional dan mengevaluasi globalisasi.

\section{E. Kesimpulan dan Rekomendasi}

\section{Kesimpulan}

Dari beberapa paparan kegiatan di atas dapat disimpulkan bahwa inovasi kurikulum madrasah di pesantren dalam implementasi Civic Education itu penting mengingat pendidikan keagamaan Islam di pesantren mempunyai kontribusi besar pada penguatan Negara Kesatuan Republik Indonesia yakni sebagai benteng moral sekaligus benteng radikalisme. Dukungan yang baik dari stakeholder internal dan eksternal juga merupakan motivasi besar pada kelancaran dan kesuksesan program kegiatan pengabdian kepada masyarakat berbasis madrasah ini. Antusias peserta dan pengelola madrasah diniyah al-Amiriyyah Blokagung Banyuwangi yang sangat baik juga merupakan energi positif yang memotivasi tim pengabdian Institut Agama Islam Darussalam Blokagung Banyuwangi untuk terus berupaya maksimal dalam pendampingan inovasi kurikulum madrasah dalam mengimplementasikan Civic Education bersama stakeholder dan para ahli dalam kegiatan pendapingan dan pengabdian pada madrasah diniyah terbesar 
di kabupaten Banyuwangi yang harapannya bisa menjadi rujukan serta barometer bagi madrasah diniyah se-kabupaten Banyuwangi.

\section{Rekomendasi}

a. Kepala Bakesbangpol dan Tim Wawasan Kebangsaan kabupaten Banyuwangi

Melanjutkan kerjasama dengan madrasah diniyah dan pesantren sekabupaten Banyuwagi dalam gerakan sosialisasi wawasan kebangsaan agar santri memahami dengan baik materi Civic Education sehingga mampu mengimplementasi dalam kehidupan sehari-hari, baik saat di pesantren berkumpul dengan temannya dari seluruh penjuru daerah Indonesia, maupun saat pulang ke daerahnya masing-masing.

b. Kasi. PD. Pontren kementerian agama kabupaten Banyuwangi

Memberikan pembinaan yang baik secara berkala dan berkelanjutan pada pendidikan diniyah baik yang dikelola oleh madrasah diniyah maupun yang dikelola oleh pesantren, mengingat afiliasi pendidikan diniyah pada kementerian agama, maka sangat besar pengaruh dan arti perhatian serta pembinaan kementerian agama pada pendidikan diniyah di madrasah maupun di pesantren untuk pengakuan dan perkembangannya.

c. Pengelola madrasah diniyah al-Amiriyyah Blokagung Banyuwangi

Melakukan inovasi kurikulum sesuai regulasi dari pemerintah dan terus membangun kerjasama dengan stakeholder terkait, supaya pendidikan diniyah yang dilaksanakan mendapat pengakuan dan pembinaan yang baik oleh stakeholder dan para ahli, sehingga mutu pendidikannya terus bisa dikembangkan dan berkontribusi besar pada pengembangan sumberdaya manusia Indonesia, khususnya pada unsur pendidikan moral dan wawasan kebangsaan.

\section{Daftar Pustaka}

Azra, Azyumardi. 2003. "Kata Pengantar", dalam Tim ICCE UIN Jakarta, Pendidikan Kewarnegaraan: Demokrasi, HAM dam Masyarakat Madani. Jakarta: ICCE UIN Syahid-TAF-Prenada Media.

Rogers, Everett. 1983. Diffusion of Innovation Third Edition. New York: The Free Press 
Sanjaya, 2009. Kurikulum dan Pembelajaran: Teori dan Praktik Pengembangan Kurikulum Tingkat Satuan Pendidikan (KTSP). Jakarta: Kencana Prenada.

Wahid, Abdurrahman. tt.Kurikulum Pesantren dan Penyediaan Lapangan Kerja “Dalam Bunga Rampai Pesantren”, Jakarta: CV Dharma Bhakti.

Ruslina. 2006. Pendidikan Kewarganegaraan. Pontianak: IAIN Pontianak Press. 